\title{
Mg-Sn-Zr Magnezyum Alaşımlarının Sıcak Pres Yöntemiyle Üretimi
}

\author{
Ali Erçetin ${ }^{1 *}$ \\ 1* Bingöl Üniversitesi, Mühendislik ve Mimarlık Fakültesi, Makine Mühendisliği Bölümü, Bingöl, Türkiye, (ORCID: 0000-0002-7631-1361), aliercetin@bingol.edu.tr
} (İlk Geliş Tarihi 23 Ocak 2021 ve Kabul Tarihi 9 Nisan 2021)

(DOI: $10.31590 /$ ejosat.866892)

ATIF/REFERENCE: Erçetin, A. (2021). Mg-Sn-Zr Magnezyum Alaşımlarının Sıcak Pres Yöntemiyle Üretimi. Avrupa Bilim ve Teknoloji Dergisi, (23), 649-655.

\begin{abstract}
$\ddot{O} \mathbf{z}$
Mg alaşımları, oldukça düşük yoğunluğuyla hafif alaşımlar grubunda yer almaktadır. Farklı alaşım elementlerinin ilavesiyle özellikle mekanik özelliklerinde gelişmeler sağlanmaktadır. İlave edilen alaşım elementlerinin mikroyapıda homojen dağılması, alaşımın özelliklerini etkileyen önemli etmenlerdendir. Bu çalışmada, ağırlıç̧a farklı oranlarda (x=\%0,5, \%1, \%1,5 ve \%2) Zr ilavesi içeren $\mathrm{Mg}$ alaşımları, sıcak presleme yöntemiyle üretilmiştir. Sinterleme prosesi, $610{ }^{\circ} \mathrm{C}$ 'de, $50 \mathrm{MPa}$ basınç altında 60 dk süreyle gerçekleştirilmiştir. $\mathrm{Mg}$ ve $\mathrm{Zr}$ tozlarının havayla temasını önlemek için, tozlar hacimce \%20 oranında parafin ile kaplanmıştır. Alaşımların yüzeyine ait mikroyapı incelemelerinde taramalı elektron mikroskobu (SEM) ve enerji dağılımlı spektrometri (EDS) analizleri uygulanmıştır. Mikroyapıdaki faz oluşumları X-1şını kırınımı (XRD) analizi ile tespit edilmiştir. Sinterleme işlemi öncesinde parafin kaplama tekniğiyle, sinterleme esnasında ise koruyucu argon gazı ile oksidasyon önlenebilmiştir. Uygulanan sıcak presleme yöntemiyle, Mg alaşımları \%98,8'in üzerinde bağıl yoğunluğa ulaşmıştır. Uygulanan sıcak presleme yöntemi, homojen mikroyapılı $\mathrm{Mg}$ alaşımlarının üretiminde etkili olmuştur. $\mathrm{Zr}$ ilavesiyle tane sınırlarında homojen bir şekilde dağılan $\alpha-\mathrm{Zr}$ fazları, mekanik özelliklerin gelişmesinde (yaklaşık ağ. \%30) etkili olmuştur.
\end{abstract}

Anahtar Kelimeler: Mg Alaşımı, Zr İlavesi, Bağıl Yoğunluk, Mikroyapı, Mekanik Özellikler.

\section{Production of Mg-Sn-Zr Magnesium Alloys Through Hot Press Method}

\begin{abstract}
$\mathrm{Mg}$ alloys are in the light alloys group with their very low density. With the addition of different alloying elements, improvements are achieved especially in mechanical properties. The homogeneous distribution of the added alloy elements in the microstructure is one of the important factors affecting the properties of the alloy. In this study, $\mathrm{Mg}$ alloys containing $\mathrm{Zr}$ addition in different proportions $(\mathrm{x}=0.5 \%, 1 \%, 1.5 \%$ and $2 \%)$ by weight were produced by hot pressing method. The sintering process was carried out at $610{ }^{\circ} \mathrm{C}$ under $50 \mathrm{MPa}$ pressure for $60 \mathrm{~min}$. In order to prevent $\mathrm{Mg}$ and $\mathrm{Zr}$ powders from contacting with air, the powders are covered with $20 \%$ paraffin by volume. Scanning electron microscopy (SEM) and energy dispersive spectrometry (EDS) analyses were applied in the microstructure studies of the surface of alloys. Phase formations in the microstructure were determined by X-ray diffraction (XRD) analysis. Oxidation could be prevented by the paraffin coating technique before the sintering process and by the protective argon gas during sintering. With the hot pressing method applied, $\mathrm{Mg}$ alloys have reached a relative density of over $98.8 \%$. The hot pressing method applied was effective in the production of homogeneous microstructure of $\mathrm{Mg}$ alloys. The $\alpha$-Zr phases, homogeneously distributed in the grain boundaries with the addition of $\mathrm{Zr}$, have been effective in the development of mechanical properties (approximately $30 \mathrm{wt} . \%$ ).
\end{abstract}

Keywords: Mg Alloy, Zr Addition, Relative Density, Microstructure, Mechanical Properties.

\footnotetext{
* Sorumlu Yazar: aliercetin@ bingol.edu.tr
} 


\section{Giriş}

Magnezyum, en hafif yapısal metaldir. Mg’ye alaşım elementi ilavesiyle, Mg alaşımlarının mekanik, korozyon ve biyo özelliklerinde önemli ölçüde gelişmeler sağlanmıştır (Candan et al., 2018; Çetin et al., 2020). Mg alaşımlarının dayanım/yoğunluk oranı, diğer metallere göre oldukça yüksektir. Bununla birlikte, iyi dökülebilirlik ve çok iyi işlenebilirlik gibi özelliklere de sahiptir. Bu özellikleri sayesinde, son yıllarda diğer yapısal malzemelere göre daha fazla tercih edilmektedirler (Wang et al., 2020; Yang et al., 2011; Yin et al., 2020). Otomotiv, havacilık, savunma, elektronik ve biyomedikal gibi uygulamalarda, Mg alaşımları önemli bir yere sahiptir (J. Li et al., 2013; Öztürk \& Kaçar, 2012; Sun et al., 2009; Yin et al., 2020).

Piyasada en sık kullanılan Mg alaşımlarında, ana alaşım elementi olarak Al ilavesi bulunmaktadır (Akkaş et al., 2018; Candan et al., 2014; Çelik, 2019). Ancak, ticari olarak temin edilebilen $\mathrm{Mg}$-Al alaşımların uygulanması, yüksek sıcaklıklarda (> $120^{\circ} \mathrm{C}$ ) zayıf sürünme davranışları ile sınırlıdır (Yang et al., 2011). Bu durum, mikroyapıda bulunan $\mathrm{Mg}_{17} \mathrm{Al}_{12}$ fazının düşük ergime sicaklığına $\left(462{ }^{\circ} \mathrm{C}\right)$ sahip olmasindan kaynaklanmaktadır (Wang et al., 2020). Sn alaşım elementi, $561^{\circ} \mathrm{C}$ 'de $\mathrm{Mg}$ içerisindeki maksimum katı çözünürlüğü ağırlıkça \%14,85 civarındadır. Oda sıcaklığına hızlı soğuma gerçekleştirildiğinde, mikroyapıda $\mathrm{Mg}_{2} \mathrm{Sn}$ fazı oluşmaktadır (Gökçe, 2020b). $\mathrm{Mg}_{2} \mathrm{Sn}$ fazının yüksek ergime sıcaklığına $\left(770^{\circ} \mathrm{C}\right)$ sahip olması, $\mathrm{Mg}$ alaşımlarının yüksek sıcaklık uygulamalarında servis ömrünü geliştirebilmektedir (Wang et al., 2020). Mg'ye ilave edilen alaşım elementlerinden $\mathrm{Zr}$, ağırlıkça $\% 0,43$ oranında ilave edildiğinde, herhangi bir yeni faz oluşmamaktadır (Pan \& Yang, 2011; Wang et al., 2020). Bu orandan daha fazla $\mathrm{Zr}$ ilave edilerek alaşım hızlı soğutulduğunda, $\mathrm{Zr}$ alaşım elementi, tane sınırlarında $\alpha$ veya $\beta$ fazında bulunabilmektedir. Alaşım elementi ilavesi kadar mekanik özellikleri etkileyen diğer bir durum ise, üretim yöntemleridir.

Günümüzde $\mathrm{Mg}$ alaşımları genellikle döküm yöntemiyle üretilmektedir (Akyüz, 2018, 2019). Döküm yönteminde farklı oranlarda alaşım elementi ilavesi, alaşımın diğer özellikleri ile birlikte dökülebilirliği de etkilemektedir (Akyüz, 2020; Elen et al., 2019). Dolayısıyla, her oranda alaşım elementi ilavesiyle döküm gerçekleştirilememektedir. Ayrıca, döküm yöntemiyle üretilen $\mathrm{Mg}$ alaşımları, tam yoğun bir yapıya sahip olmadığı için alaşımlara ilave proses olarak ekstrüzyon işlemi uygulanmaktadır (Mert, 2018). Bununla birlikte, mikroyapıda segregasyon oluşumları da gerçekleşebilmektedir. $\mathrm{Bu}$ sebeple döküm sonrası ayrıca bir homojenizasyon işlemi uygulanabilmektedir (Q. Liu et al., 2018; Özgün et al., 2020). Homojen bir mikroyapı eldesinde TM yöntemi etkili yöntemlerdendir (Erden, 2016a; Gökçe, 2020a; Özgün \& Erçetin, 2017). Ancak, Mg alaşımları geleneksel TM yöntemiyle üretildiğinde alaşımlarda tam yoğunlaşma gerçekleştirilememektedir. Dolayısıyla, toz metalurjisi tekniklerinden sıcak presleme yönteminde, sinterleme ve basınç eş zamanlı uygulanmakta ve yoğun mikroyapıya sahip $\mathrm{Mg}$ alaşımları üretilebilmektedir (Aydoğmuş et al., 2020; Erçetin et al., 2020).

Bahsedilen literatür çalışmalarına göre, $\mathrm{Mg}$ alaşımlarının sıcak presleme metoduyla üretimine dair çok az sayıda çalışma olduğu anlaşılmaktadır. Aynı şekilde, sıcak presleme yöntemiyle e-ISSN: 2148-2683 üretilen $\mathrm{Zr}$ içerikli $\mathrm{Mg}$ alaşımlarına ait çalışmalar da literatürde yok denecek kadar azdır. Bu çalışmada, farklı oranlarda $\mathrm{Zr}$ içeriğine sahip $\mathrm{Mg} 6 \mathrm{Sn}$-xZr alaşımı sıcak presleme yöntemiyle üretilmiştir. Üretilen alaşımların mikroyapısal ve mekaniksel özellikleri incelenmiştir.

\section{Materyal ve Metot}

Çalışmada, yüksek saflıkta ve mikron boyutlarında $\mathrm{Mg}(<45$ $\mu \mathrm{m})$, Sn $(<10 \mu \mathrm{m}), \operatorname{Mn}(<15 \mu \mathrm{m})$ ve $\mathrm{Zr}(<5 \mu \mathrm{m})$ tozlarının tartılması ve belirlenen kompozisyonlarda karıştırılması aşamalarında, tozların oksidasyona maruz kalması veya karıştırma esnasında tozların sürtünmesinden kaynaklı olarak tutuşma riski vardır. $\mathrm{Bu}$ nedenle, $\mathrm{Mg}$ ve $\mathrm{Zr}$ tozları çalışmanın başlangıcında parafin kaplama tekniği ile hacimce $\% 20$ oranında parafin ile kaplanmıştır. Mg ve $\mathrm{Zr}$ tozlarının parafin kaplanması tekniğine ait ayrıntılı bilgiler geçmiş deneysel çalışmalarımızda görülebilir (Ercetin et al., 2020, 2021). Toz metalurjisi yönteminde karıştırma süresinin tozların homojen karışmasında önemli ölçüde etkisi vardır (Erden, 2016b). Şimdiki çalışmada, parafin kaplama esnasında optimum karıştırma süresi, $180 \mathrm{rpm}$ ve 1 saat uygulanmıştır. Tozların tartılmasında Precisia marka $\left(10^{-4}\right.$ hassasiyetinde) hassas terazi kullanılmıştır.

Tablo 1. Farklı oranlarda $\mathrm{Zr}$ içeren $\mathrm{Mg}$ alaşımlarının kimyasal bileşimi

\begin{tabular}{|c|c|c|c|c|}
\hline $\begin{array}{c}\text { Alaşım } \\
\text { Kodu }\end{array}$ & $\begin{array}{c}\text { Sn } \\
\text { (ăg.\%) }\end{array}$ & $\begin{array}{c}\text { Mn } \\
(\mathbf{a g ̆ . \% )}\end{array}$ & $\begin{array}{c}\mathbf{Z r} \\
(\mathbf{a g ̆} \%)\end{array}$ & $\begin{array}{c}\text { Mg } \\
(\mathbf{a g ̆ . \% )}\end{array}$ \\
\hline TK-1 & 6 & 0,1 & 0,5 & Kalan \\
\hline TK-2 & 6 & 0,1 & 1 & Kalan \\
\hline TK-3 & 6 & 0,1 & 1,5 & Kalan \\
\hline TK-4 & 6 & 0,1 & 2 & Kalan \\
\hline
\end{tabular}

Tablo 1'de belirtilen oranlarda sağlanan karışımlar, 30x10 mm ölçülerindeki grafit kalıp içerisine doldurulmuştur. Öncelikle tüm alaşımlar, $300^{\circ} \mathrm{C}$ sıcaklıkta bağlayıcı giderme işlemine tabi tutulmuş, daha sonra $610^{\circ} \mathrm{C}$ 'de $50 \mathrm{MPa}$ basınç altında $60 \mathrm{dk}$ süreyle sinterlenmiştir. Sinterleme esnasında oksidasyonu önlemek için koruyucu argon gazı kullanılmıştır. Sinterlenen numunelere sırasıyla zımparalama, parlatma ve dağlama işlemleri uygulanmıştır. Dağlama sıvısı olarak hacimce $\% 5$ nitrik asit ve \%95 etil alkol karışımı kullanılmıştır. Sinterleme sonrası üretilen alaşımların mikroyapısında oluşan fazların tayini için, XRD analizinden yararlanılmıştır. $\mathrm{Mg}$ alaşımlarının mikroyapı yüzey morfolojisi için SEM-EDS analizleri uygulanmıştır. Alaşımların teorik yoğunluğu Tablo 1'de belirtilen oranlar dikkate alınarak belirlenmiştir. Arşimed prensibinden yararlanılarak, alaşımların gerçek yoğunluk değerleri literatür çalışmaları doğrultusunda ölçülmüştür (Ercetin et al., 2021; Majeed et al., 2020; Özgün et al., 2020).

Mekanik özelliklerin belirlenmesinde mikro Vickers sertlik testleri uygulanmıştır. Mikro testler, 10 saniye süreyle $200 \mathrm{gr}$ yük altında, her bir alaşım yüzeyinin 5 farklı noktasından alınarak gerçekleştirilmiştir. 5 noktadan alınan ölçümlerin ortalaması, ilgili alaşımın sertlik değeri olarak kabul edilmiştir.

\section{Araştırma Sonuçları ve Tartışma}

\subsection{Yoğunluk Ölçümlerinin Değerlendirilmesi}

Farklı oranlarda $\mathrm{Zr}$ ilavesi içeren $\mathrm{Mg}$ alaşımlarının, sinterleme sonrası ölçülen yoğunluk, teorik yoğunluk ve (\%) 650 
bağıl yoğunluk değerleri Şekil 1'de verilmektedir. Artan $\mathrm{Zr}$ ilavesine bağlı olarak, teorik ve ölçülen yoğunluk değerleri artmaktadır. Ancak, ölçülen yoğunluk değerlerindeki artışa rağmen, bağıl yoğunluk değerleri azalmaktadır. (\%) Bağıl yoğunluk değerleri, ölçülen yoğunlukların teorik yoğunluklara oranlanmasıyla elde edilmektedir. Şekil 1'deki ölçülen ve teorik yoğunluk grafikleri beraber incelendiğinde artış eğimleri farklılık göstermektedir. Ancak, minimum ve maksimum bağıl yoğunluk değerleri arasında çok az bir farklılık $(<\% 1)$ bulunmaktadır. Toz metalürjisi ile yapılan üretimlerde, bağıl yoğunluğun belirli bir oranın $(\geq \% 95)$ üzerinde elde edilmesi, sinterlemenin başarılı olduğunu ifade etmektedir (Majeed et al., 2020; Özgün et al., 2015). Şimdiki çalışmada ise, minimum (\%) bağıl yoğunluk değeri, \%98,8 olarak TK4 magnezyum alaşımından elde edilmiş ve literatürde belirtilen orandan oldukça yüksektir (Majeed et al., 2020; Özgün et al., 2015).

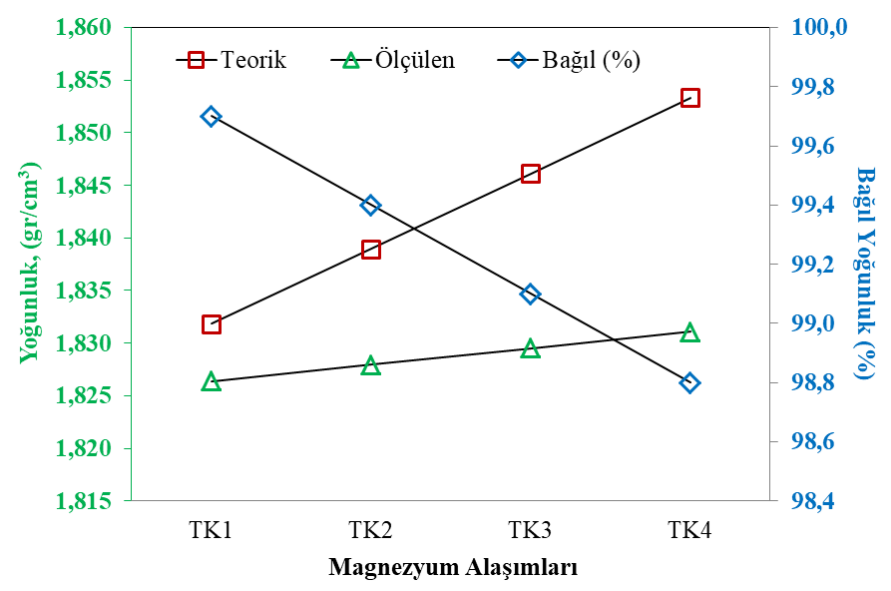

Şekil 1. Farklı oranlarda Zr içeren Mg alaşımlarının teorik, ölçülen ve bă̆ll yoğunluk değerleri

\subsection{XRD Analizi}

Sicak presleme yöntemiyle üretilen $\mathrm{Zr}$ ilaveli $\mathrm{Mg}$ alaşımlarına ait XRD desenleri Şekil 2'de verilmiştir. Alaşımların XRD desenleri, $\alpha-\mathrm{Mg}, \mathrm{Mg}_{2} \mathrm{Sn}$ ve $\alpha-\mathrm{Zr}$ piklerini içermektedir. Her bir alaşıma ait XRD desenleri incelendiğinde, herhangi bir oksijen $(\mathrm{O})$ içerikli faza rastlanmamıştır. Bu durum, sinterleme prosesinin argon koruyucu gaz atmosferinde başarılı bir şekilde gerçekleştirildiğine işaret etmektedir. $\mathrm{Mg}_{2} \mathrm{Sn}$ fazına ait pikler, her bir alaşımda yaklaşık aynı şiddetlerde olduğu görülmektedir. Literatür çalışmalarına göre (H. Liu et al., 2007), Mg'ye ağırlıkça \%5'ten daha fazla $\mathrm{Sn}$ ilave edildiğinde, $\mathrm{Mg}_{2} \mathrm{Sn}$ fazları elde edilmiştir. Şimdiki çalışmada da, \%6 Sn ilavesine bağlı olarak, $\mathrm{Mg}$ alaşımlarında $\mathrm{Mg}_{2} \mathrm{Sn}$ fazlarının varlığ edilmiştir. Alaşımların içerdiği $\mathrm{Zr}$ oranındaki artışla birlikte, $\alpha$ Zr'nin bulunduğu pikler artış göstermiştir. $\alpha-Z r$ fazına ait pikler, benzer bir çalışmadaki XRD analizinde, aynı açı değerlerinde tespit edilmiştir (Kim et al., 2019).

\subsection{EDS ve SEM Analizleri}

Şekil 3’te, ağırlıkça \%2 Zr içeren (TK4) Mg alaşımına ait 1000x büyütmede alınan SEM görüntüsü ile EDS analizi sonuçları verilmektedir. SEM görüntüsü üzerinde 3 farklı bölgeden (tane içi ve tane sınırlarından) elementel analiz sonuçları alınmıştır. İntermetalik fazların tane sınırlarında yoğun miktarda çökeldiği net bir şekilde görülmektedir. Tane içleri koyu gri renkli, tane sınırları ise beyaz ve açık gri renkli yapılardan oluşmaktadır.

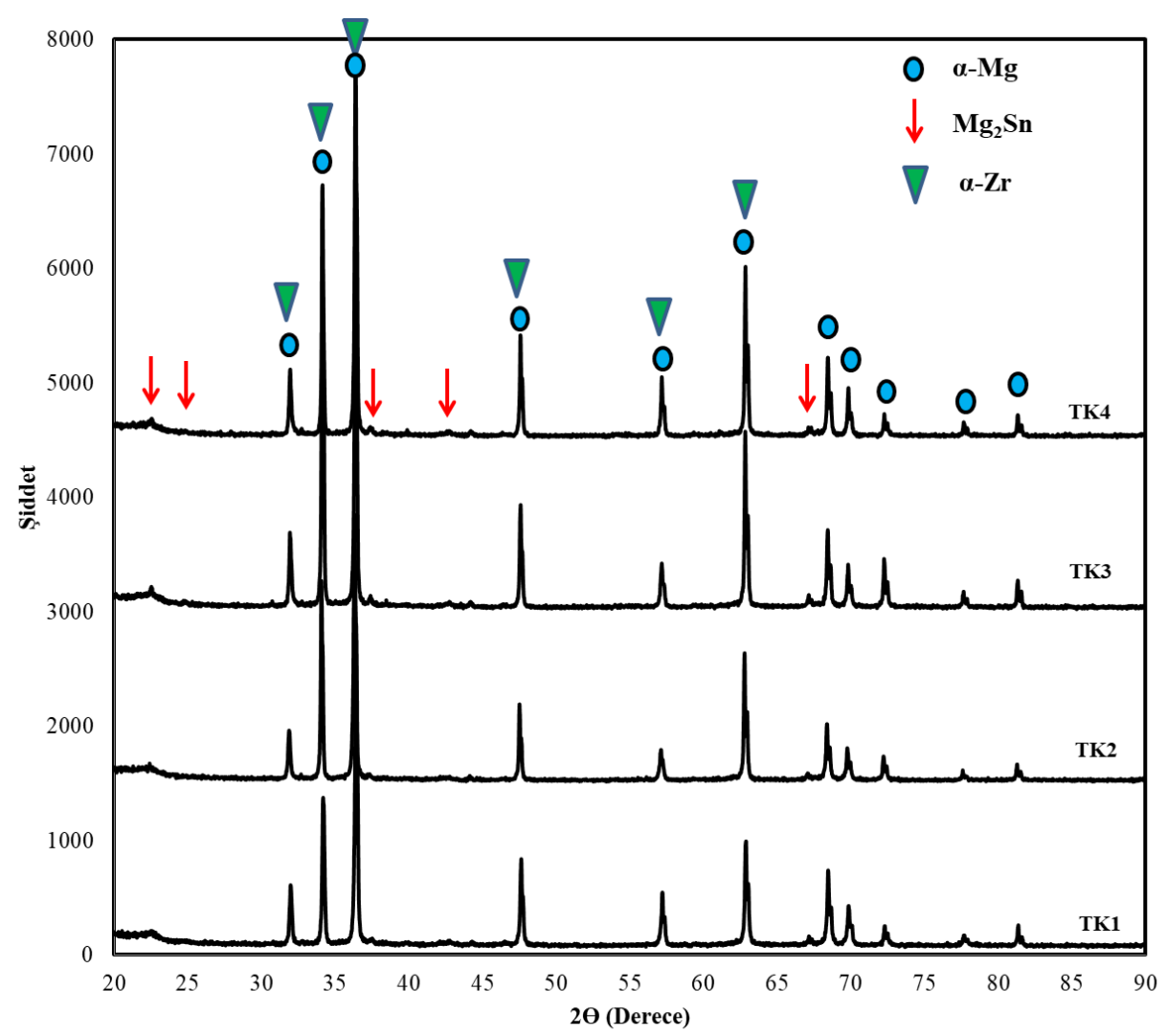

Şekil 2. Farklı oranlarda Zr içeren Mg alaşımlarının XRD desenleri 


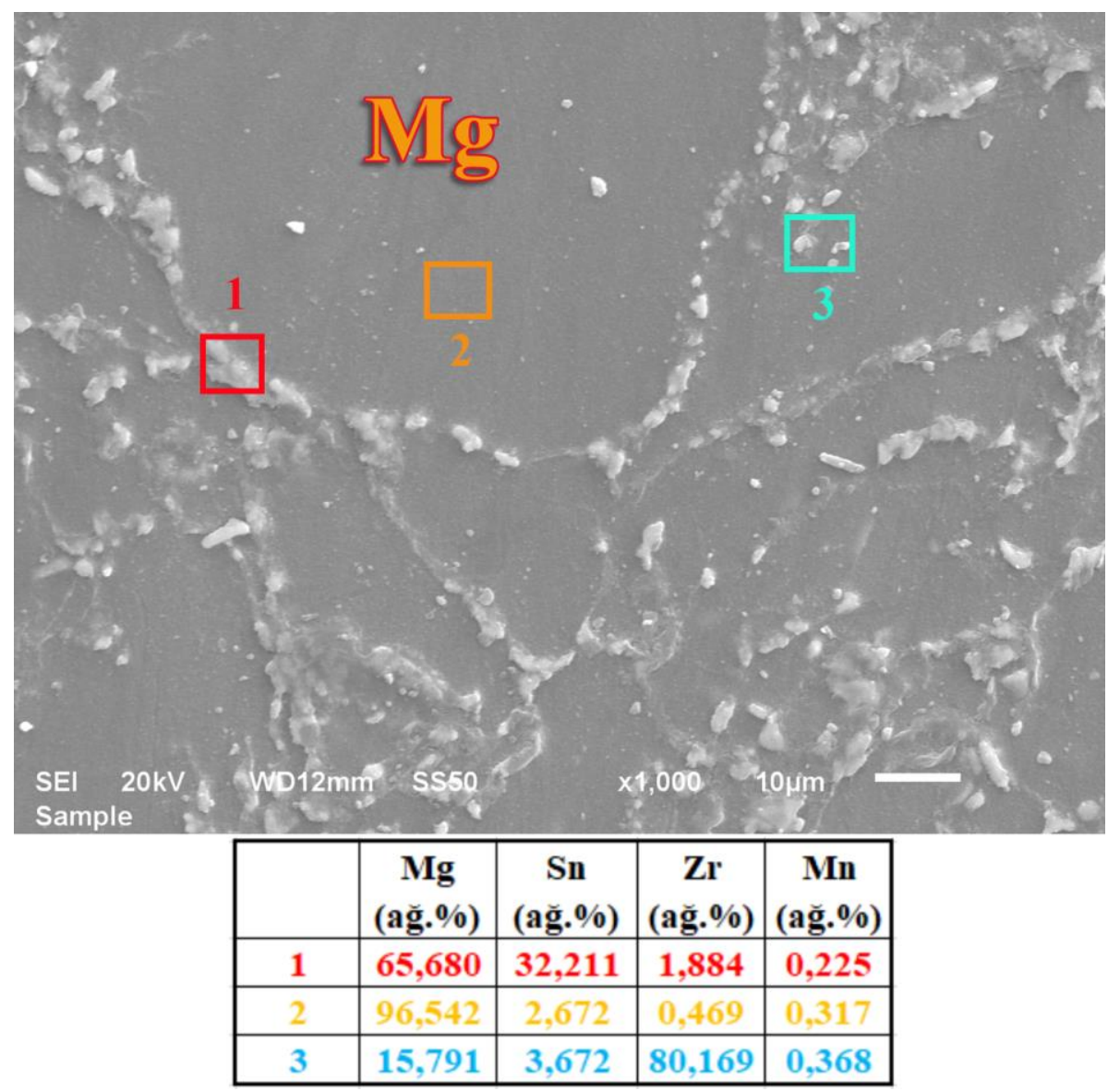

Şekil 3. Ağırlıkça \%2 Zr içeren Mg alaşımına ait noktasal EDS analizi

1 nolu bölgede $\mathrm{Mg}$ ve Sn içeriklerinin oldukça fazla olduğu görülmektedir. $\mathrm{Bu}$ bölgenin, XRD analizinde tespit edilen $\mathrm{Mg}_{2} \mathrm{Sn}$ faz içeriği bakımından zengin olduğu düşünülmektedir. 2 nolu bölgede (tane içi), sadece $\mathrm{Mg}$ içeriğinin zengin olduğu tespit edilmiştir. Tane içlerinde diğer alaşım elementlerinin de bulunması, bu elementlerin oda sıcaklı̆̆ında $\mathrm{Mg}$ içerisinde katı çözelti oluşturduğuna işaret etmektedir. 3 nolu bölgede belirtilen beyaz renkli, ince ve oldukça küçük yapılar $\mathrm{Zr}$ içeriği bakımından oldukça zengindir. $\mathrm{Bu}$ yapılar tane sınırlarında homojen ve süreksiz bir şekilde dizilmektedir.

Sıcak presleme yöntemiyle üretilen $\mathrm{Mg}$ alaşımlarının 500x büyütmede alınan SEM görüntüleri Şekil 4 'te verilmektedir. Her bir alaşıma ait SEM görüntüleri incelendiğinde, mikroyapıların gözeneksiz, ince taneli ve oldukça yoğun yapılarda olduğu belirlenmiştir. Pan ve Yang'ın benzer çalışmasında da (Pan \& Yang, 2011), Zr ilavesiyle mikroyapıda daha ince taneli yapılar elde edilmiştir. XRD ve EDS analizlerinde tespit edilen fazlar, tane sınırlarında yoğunlaşmış ve homojen olarak dağılmıştır. Yüksek oranda $\mathrm{Zr}$ alaşım elementinin ilave edildiği SEM görüntüsünde (Şekil 4d), tane sınırlarının süreksiz ve kesikli bir yapıya dönüştüğü ve EDS analizinde tespit edilen $\mathrm{Zr}$ içeriği bakımından zengin olan beyaz yapıların arttı̆̆ 1 görülmektedir. $\mathrm{Bu}$ durumun sertlik özelliklerini olumlu etkilediği düşünülmektedir. 

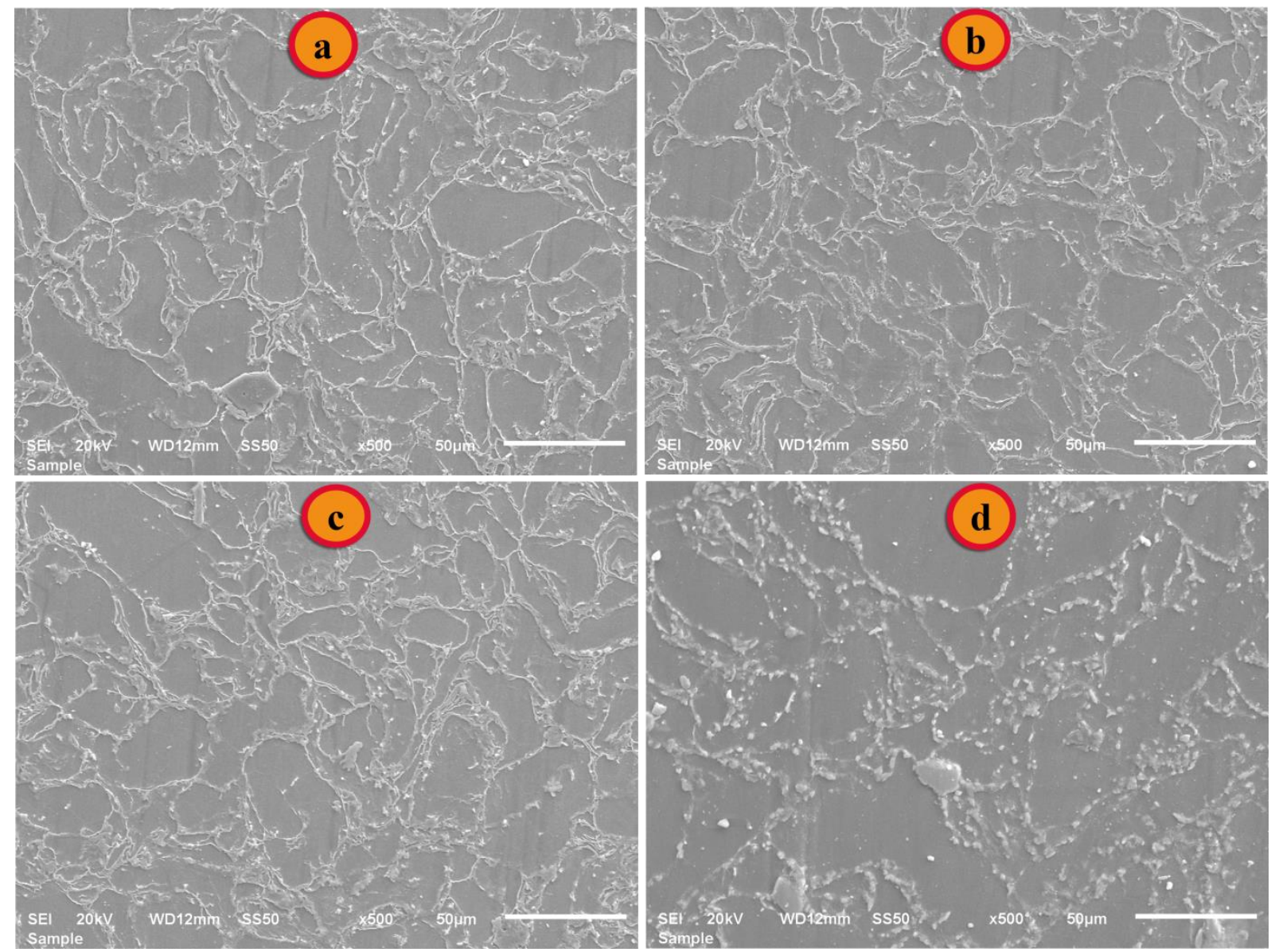

Şekil 4. Sıcak presleme yöntemiyle üretilen Mg alaşımlarının SEM görüntüleri; (a) TK1, (b) TK2, (c) TK3, (d) TK4

\subsection{Sertlik Özelliklerinin Değerlendirilmesi}

Ağırlıç̧a \%0,5, 1, 1,5 ve 2 oranlarında $\mathrm{Zr}$ içeren $\mathrm{Mg}$ alaşımlarına ait mikro-sertlik ve ölçülen yoğunluk grafikleri birlikte Şekil 5'te verilmiştir. $\mathrm{Mg}$ alaşımlarının içerdiği $\mathrm{Zr}$ oranındaki artışa bağlı olarak mikro-sertlik değerleri de artış göstermiştir. Artan $\mathrm{Zr}$ ilavesiyle birlikte, herbir alaşımın minimum ve maksimum sertlik değerleri arasındaki fark da artmaktadır. Bu durumun, artan $\mathrm{Zr}$ içeriğine bağlı olarak $\mathrm{Mg}$ alaşımlarının bağıl yoğunluklarının azalmasından kaynaklandığı düşünülmektedir. En yüksek mikro-sertlik değeri $68,4 \mathrm{HV}_{0,2}$ ile TK4 alaşımından, en düşük mikro-sertlik değeri ise $62,4 \mathrm{HV}_{0,2}$ ile TK1 alaşımından elde edilmiştir.

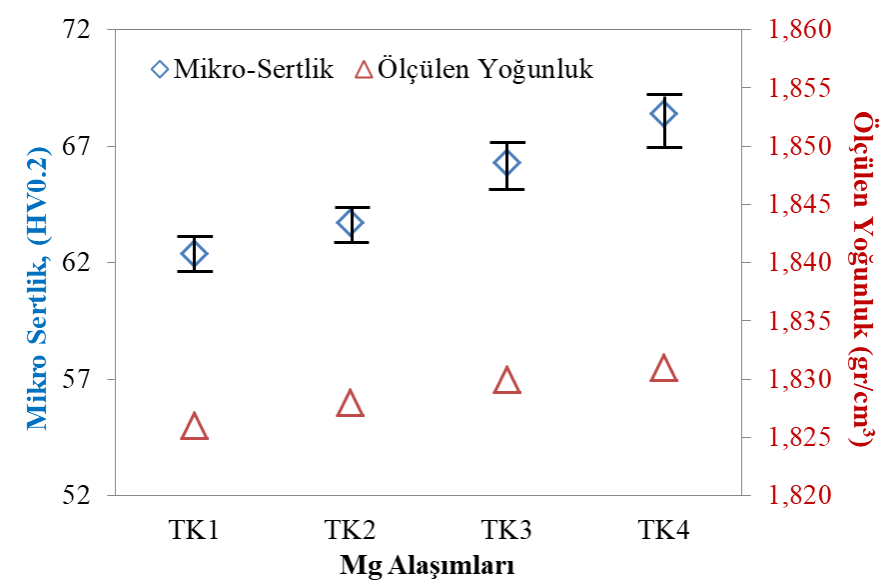

Şekil 5. Mg alaşımlarına ait mikro sertlik ve ölçülen yoğunluk değerleri
Literatürde Turan vd. ait benzer bir çalışmada (Turan et al., 2017), sıcak presleme yöntemiyle saf $\mathrm{Mg}$ üretilmiş ve maksimum 41,7 $\mathrm{HV}_{(0,5)}$ sertlik değeri elde edilmiştir. Şimdiki çalışmada, en iyi mekanik özelliklerin elde edildiği TK4 koduna sahip Mg alaşımı, Turan vd. elde ettiği sonuçtan \%64 daha fazladır. Li vd. çalışmasına göre ise (W. Li et al., 2017), döküm yöntemiyle üretilen $\mathrm{Mg} 7 \mathrm{Sn}$ magnezyum alaşımı en yüksek 52,6 $\mathrm{HV}_{(0,2)}$ mikro sertlik değerine ulaşabilmiştir. Mevcut $\mathrm{Zr}$ ilaveli çalışmada elde edilen sertlik değerleri, Li vd. elde ettiği sonuçtan da $\% 30$ daha yüksektir.

\section{Sonuçlar}

Çalışmada, magnezyuma sabit oranlarda $\mathrm{Sn}$ ve $\mathrm{Mn}$ alaşım elementleri ile ağırlıkça farklı oranlarda $(\mathrm{x}=\% 0,5, \% 1, \% 1,5$ ve \%2) $\mathrm{Zr}$ ilavesi yapılmış ve sıcak presleme yöntemiyle $\mathrm{Mg}$ alaşımlarının üretimi başarıyla gerçekleştirilmiştir. Üretilen alaşımların mikroyapısal ve mekanik özellikleri incelenmiştir. Elde edilen sonuçlar şu şekildedir:

$>\mathrm{Mg}$ ve $\mathrm{Zr}$ tozlarına parafin kaplama tekniği uygulanarak, $\mathrm{TM}$ yönteminin $\mathrm{Mg}$ alaşımlarına uygulanabilirliğinde gelişme sağlanmıştır.

$>$ Sinterlenen alaşımların hızlı soğutulmasında sıcak presleme yöntemi etkili olmuştur.

$>$ Sicak presleme yöntemi ile yüksek bağıl yoğunluklu Mg alaşımları üretilebilmektedir.

> Artan $\mathrm{Zr}$ ilavesi bağıl yoğunluğu olumsuz etkilemiştir.

$>$ Alaşımların mikroyapısında $\alpha-\mathrm{Mg}, \mathrm{Mg}_{2} \mathrm{Sn}$ ve $\alpha-\mathrm{Zr}$ fazları tespit edilmiştir. 
> Yoğun ve homojen mikroyapıya sahip alaşımlar üretilmiştir.

$>\mathrm{Mg}$ alaşımına $\mathrm{Zr}$ ilavesi mekanik özellikleri geliştirmektedir.

Zr ilave oranının mevcut çalışmada belirtilen oranlardan çok daha yüksek seçilmesi durumunda, sinterleme sıcaklığının arttırılması önerilir.

\section{Teşekkür}

$\mathrm{Mg}$ alaşımlarının mikroyapısal incelemelerinde (XRD ve SEM-EDS analizleri) gayret sarf eden Bingöl Üniversitesi Merkezi Laboratuvarına ve çalışanlarına teşekkür ederim. Sertlik cihazı ve sıcak presleme cihaz temini sağlayan Bingöl Üniversitesine ayrıca teşekkürlerimi sunarım.

\section{Kaynakça}

Akkaş, M., Çetin, T., \& Boz, M. (2018). Gaz atomizasyonu yöntemi ile AM60 magnezyum alaşım tozu üretimi ve karakterizasyonu. SDU International Journal of Technological Sciences, 10(3), 1-9.

Akyüz, B. (2018). AS21 ve AJ21 magnezyum alaşımlarının mekanik ve işlenebilirlik özelliklerinin incelenmesi. $B S ̧ E \ddot{U}$ Fen Bilimleri Dergisi, 5(2), 105-111.

Akyüz, B. (2019). AZ21 ve AJ21 magnezyum alaşımlarının mekanik özellikleri ve işlenebilirliği. Düzce Üniversitesi Bilim ve Teknoloji Dergisi, 7(3), 1019-1028.

Akyüz, B. (2020). AZ91, AS91 ve AM90 magnezyum alaşımlarının aşınma ve 1sıl davranışları üzerine karşılaştırmalı bir çalışma. BŞEÜ Fen Bilimleri Dergisi, 7(2), 1075-1083.

Aydoğmuş, T., Kelen, F., \& Aydemir, E. (2020). Sicak presleme yöntemi ile AZ91 magnezyum alaşımının üretimi. BEÜ Fen Bilimleri Dergisi, 9(1), 277-287.

Candan, Ş., Çelik, M., \& Candan, E. (2014). AZ91 magnezyum alaşımında soğuma hızlarının mekanik ve korozyon özelliklerine etkisi. BŞEÜ Fen Bilimleri Dergisi, 1(2), 1728.

Candan, Ş., Çim, S., Emir, S., \& Candan, E. (2018). AZ serisi $\mathrm{Mg}$ alaşımlarının korozyon davranışlarında $\beta$-fazının rolü. Düzce Üniversitesi Bilim ve Teknoloji Dergisi, 6(4), 11391162.

Çelik, İ. (2019). Yüzey işlemi uygulanmış AZ31 Mg alaşımının yapısal özelliklerinin ve aşınma davranışının incelenmesi. Gümüşhane Üniversitesi Fen Bilimleri Enstitüsü Dergisi, 9(1), 136-142.

Çetin, T., Akkaş, M., \& Boz, M. (2020). Gaz atomizasyonu yöntemi ile üretilen AM60 magnezyum alaşım tozunun toz karakterizasyonu üzerine gaz basıncının etkisinin araştırılması. Journal of the Faculty of Engineering and Architecture of Gazi University, 35(2), 967-977.

Elen, L., Türen, Y., \& Koç, E. (2019). AZ91 Mg alaşımına farklı oranlarda Sb ilavesi ile katılaşma hızının mikroyapı ve mekanik özelliklere etkisi. Uluslararası Mühendislik Araştırma ve Geliştirme Dergisi, 11(2), 451-463.

Erçetin, A., Aslantas, K., \& Özgün, Ö. (2020). Micro-end milling of biomedical Tz54 magnesium alloy produced through powder metallurgy. Machining Science and Technology, 24(6), 924-947. https://doi.org/10.1080/10910344.2020.1771572

Ercetin, A., Özgün, Ö., \& Aslantas, K. (2021). Investigation of Mechanical Properties of Mg5Sn-xZn Alloys Produced through New Method in Powder Metallurgy. Journal of Testing and Evaluation, 49(5), 20200020. https://doi.org/10.1520/jte20200020

Ercetin, A., Özgün, Ö., Aslantas, K., \& Aykutoğlu, G. (2020). The microstructure, degradation behavior and cytotoxicity effect of $\mathrm{Mg}-\mathrm{Sn}-\mathrm{Zn}$ alloys in vitro tests. SN Applied Sciences, 2(2), 1-12. https://doi.org/10.1007/s42452-0201988-9

Erden, M. A. (2016a). Effect of C content on microstructure and mechanical properties of $\mathrm{Nb}-\mathrm{V}$ added microalloyed steel produced by powder metallurgy method. Avrupa Bilim ve Teknoloji Dergisi, 5(9), 44-47.

Erden, M. A. (2016b). Karıştırma süresinin toz metalürjisi ile üretilen alaşımsız çeliklerin mekanik özelliklerine etkisi. Avrupa Bilim ve Teknoloji Dergisi, 5(9), 62-65.

Gökçe, A. (2020a). Magnezyum ve alaşımlarının toz metalurjisi işlemleri. Düzce Üniversitesi Bilim ve Teknoloji Dergisi, $8(1), 522-534$.

Gökçe, A. (2020b). Toz metalurjisi yöntemiyle Mg-Sn alaşımı üretimi ve karakterizasyonu. Academic Platform Journal of Engineering and Science, 8(1), 112-119.

Kim, M., An, S., Huh, C., \& Kim, C. (2019). Development of zirconium-based alloys with low elastic modulus for dental implant materials. Applied Sciences, 9(24), 5281.

Li, J., Chen, R., Ma, Y., \& Ke, W. (2013). Effect of Zr modification on solidification behavior and mechanical properties of Mg-Y-RE (WE54) alloy. Journal of Magnesium and Alloys, 1(4), 346-351. https://doi.org/10.1016/j.jma.2013.12.001

Li, W., Huang, X., \& Huang, W. (2017). Effects of Ca, Ag addition on the microstructure and age-hardening behavior of a Mg-7Sn (wt\%) alloy. Materials Science and Engineering A, 692, 75-80. https://doi.org/10.1016/j.msea.2017.03.066

Liu, H., Chen, Y., Tang, Y., Wei, S., \& Niu, G. (2007). The microstructure, tensile properties, and creep behavior of ascast Mg-(1-10)\%Sn alloys. Journal of Alloys and Compounds, 440(1-2), 122-126. https://doi.org/10.1016/j.jallcom.2006.09.024

Liu, Q., Ma, Q. xian, Chen, G. qiang, Cao, X., Zhang, S., Pan, J. luan, Zhang, G., \& Shi, Q. yu. (2018). Enhanced corrosion resistance of AZ91 magnesium alloy through refinement and homogenization of surface microstructure by friction stir processing. Corrosion Science, 138, 284-296. https://doi.org/10.1016/j.corsci.2018.04.028

Majeed, A., Zhang, Y., Lv, J., Peng, T., Atta, Z., \& Ahmed, A. (2020). Investigation of T4 and T6 heat treatment influences on relative density and porosity of AlSil0Mg alloy components manufactured by SLM. Computers and Industrial Engineering, 139, 106194. https://doi.org/10.1016/j.cie.2019.106194

Mert, F. (2018). A comparision of the dry sliding wear behavior of as-cast and hot rolled AZ31B magnesium alloy. ÖHÜ Mühendislik Bilimleri Dergisi, 7(1), 417-426.

Özgün, Ö., Aslantaş, K., \& Erçetin, A. (2020). Powder Metallurgy Mg-Sn alloys: Production and characterization. Scientia Iranica, 27(3), 1255-1265. https://doi.org/10.24200/SCI.2019.50212.1578

Özgün, Ö., \& Erçetin, A. (2017). Microstructural and mechanical properties of $\mathrm{Cr}-\mathrm{C}$ reinforced $\mathrm{Cu}$ matrix composites produced through powder metallurgy method. Turkish Journal of Nature and Science, 6(2), 1-6.

Özgün, Ö., Yılmaz, R., Gülsoy, H. Ö., \& Fındık, F. (2015). Toz 
enjeksiyon kalıplama yöntemi ile üretilen 718 süperalaşım parçaların kırılma tokluğu ve darbe dayanımı özellikleri. Türk Doğa ve Fen Dergisi, 4(1), 1-7.

Öztürk, F., \& Kaçar, İ. (2012). Magnezyum alaşımları ve kullanım alanlarının incelenmesi. Niğde Üniversitesi Mühendislik Bilimleri Dergisi, 1(1), 12-20.

Pan, F., \& Yang, M. (2011). Preliminary investigations about effects of $\mathrm{Zr}$, Sc and Ce additions on as-cast microstructure and mechanical properties of Mg-3Sn-1Mn (wt.\%) magnesium alloy. Materials Science and Engineering A, 528(15), 4973-4981. https://doi.org/10.1016/j.msea.2011.02.095

Sun, M., Wu, G., Wang, W., \& Ding, W. (2009). Effect of Zr on the microstructure, mechanical properties and corrosion resistance of Mg-10Gd-3Y magnesium alloy. Materials Science and Engineering A, 523(1-2), 145-151. https://doi.org/10.1016/j.msea.2009.06.002

Turan, M. E., Sun, Y., Akgul, Y., Turen, Y., \& Ahlatci, H. (2017). The effect of GNPs on wear and corrosion behaviors of pure magnesium. Journal of Alloys and Compounds, 724, 14-23. https://doi.org/10.1016/j.jallcom.2017.07.022

Wang, F., Feng, Y., Li, M., \& Teng, X. (2020). Effect of Ca and $\mathrm{Zr}$ additions and aging treatments on microstructure and mechanical properties of Mg-Sn alloy. Materials Science Forum, 993 MSF, $152-160$. https://doi.org/10.4028/www.scientific.net/MSF.993.152

Yang, M., Liang, X., Yi, Z., \& Pan, F. (2011). Effects of zirconium addition on as-cast microstructure and mechanical properties of Mg-3Sn-2Ca magnesium alloy. Materials and Design, 32(4), 1967-1973. https://doi.org/10.1016/j.matdes.2010.11.071

Yin, S., Duan, W., Liu, W., Wu, L., Yu, J., Zhao, Z., Liu, M., Wang, P., Cui, J., \& Zhang, Z. (2020). Influence of specific second phases on corrosion behaviors of $\mathrm{Mg}-\mathrm{Zn}-\mathrm{Gd}-\mathrm{Zr}$ alloys. Corrosion Science, 166, 108419. https://doi.org/10.1016/j.corsci.2019.108419 